Check for updates

Cite this: RSC Adv., 2017, 7, 39906

\title{
A rolling circle amplification signal-enhanced immunosensor for ultrasensitive microcystin-LR detection based on a magnetic graphene- functionalized electrode
}

\author{
Zuyu He, Jie Wei, Cuifen Gan, Weipeng Liu* and Yingju Liu (DD*
}

\begin{abstract}
A novel competitive immunosensor for the sensitive and selective detection of MC-LR was developed. Magnetic graphene was synthesized, characterized and used as the substrate to immobilize antigens onto the electrode surface due to its surface area and easy separation. Furthermore, gold nanorods were modified with polydopamine and then functionalized with a secondary-antibody and circularization DNA template. By using rolling circle amplification, the DNA template can be replicated to generate extensive repeated DNA sequences, and then hybridized with the detection probe, and thus the signal was remarkably improved. Under the optimal conditions, the proposed immunosensor showed a good linear relationship between the current response and the concentration of MC-LR in the range of 0.01-50 $\mu \mathrm{g}$ $\mathrm{L}^{-1}$ with a detection limit of $0.007 \mu \mathrm{g} \mathrm{L^{-1 }}$. The immunosensor was proved to be specific, reproducible and stable. Most importantly, the proposed biosensor was applied to detect MC-LR in a real water sample with good recovery, indicating its potential application in environmental monitoring.
\end{abstract}

Received 13th July 2017

Accepted 8th August 2017

DOI: $10.1039 / \mathrm{c} 7 \mathrm{ra0} 07696 \mathrm{~g}$

rsc.li/rsc-advances

metal ions ${ }^{12}$ and other small molecules ${ }^{13}$ due to their intrinsic

\section{Introduction}

Cyanotoxins, produced by cyanobacteria or blue-green algae in eutrophic water, are harmful to the health of people and animals across the globe. ${ }^{1}$ Microcystins (MCs), one of the most common and hazardous cyanotoxins, have been identified to comprise more than 90 structural variants. ${ }^{2}$ Exposure to water contaminated with MCs can result in severe hepatic injury, since MCs can damage the liver by inhibiting the activity of protein phosphatases 1 and 2A. ${ }^{3}$ Among all MCs, microcystinleucine-arginine (MC-LR) is the most widespread and toxic. The World Health Organization (WHO) recommends that the limit of MC-LR should be less than $1 \mu \mathrm{g} \mathrm{L}{ }^{-1}$ in drinking water. ${ }^{4}$ Up to now, many analytical techniques have been developed to detect MC-LR, such as high-performance liquid chromatography (HPLC), ${ }^{5}$ enzyme-linked immunosorbent assays (ELISA), ${ }^{6}$ mass spectrometry ${ }^{7}$ and protein phosphatase inhibition assays. ${ }^{8}$ However, these methods always need expensive instruments, skilled technicians and complex pre-treatment. Therefore, it is still in need to find precise and sensitive method for qualitative and quantitative determination of MCLR.

For the last decades, various immunoassay techniques have been developed to detect virus, ${ }^{9}$ protein, ${ }^{10}$ nucleic acid,,${ }^{11}$ heavy

Department of Applied Chemistry, College of Materials \& Energy, South China Agricultural University, Guangzhou 510642, China. E-mail: weipeng_liu@scau.edu. cn; liuyingju@hotmail.com; Fax: +86-20-85282366; Tel: +86-20-85280319 characteristics, such as sensitive, selective, time-saving and lowcost. The prerequisite of an electrochemical immunosensor is based on the immobilization of the recognition elements such as antigen or antibody onto the electrode surface. Therefore, appropriate nanomaterials to modify electrode surface can improve the sensitivity and lower the detection limit of an electrochemical immunosensor. Recently, $\mathrm{Fe}_{3} \mathrm{O}_{4}$ nanoparticles have been applied in toxin-removal, ${ }^{14}$ food analysis ${ }^{15}$ and biosensor, ${ }^{16}$ since they have the abilities of excellent electrical conductivity, biocompatibility and large surface-to-volume ratio. However, raw $\mathrm{Fe}_{3} \mathrm{O}_{4}$ nanoparticles are lack of active functional groups upon their surfaces, thus it is important to modify them with versatile materials to couple antigen, antibody or other compounds.

In recent years, the two-dimensional carbon nanomaterial graphene becomes the star in nanomaterial family due to its exceptional high surface area, surface functionalization, biocompatibility and high electrical conductivity. ${ }^{17}$ Graphene, graphene oxide (GO), reduced graphene oxide (RGO) and their composites have been investigated in many fields, especially in biosensors. ${ }^{18}$ The materials that combined GO or RGO with $\mathrm{Fe}_{3} \mathrm{O}_{4}$ exhibit excellent properties, ${ }^{19}$ thus their application in electrode-modified materials is promising and worthy to be exploited. But it should be noted that the direct assembly of $\mathrm{Fe}_{3} \mathrm{O}_{4}$ on graphene is still a challenge. Polydopamine (PDA), a natural glue formed by spontaneous self-polymerization of dopamine in the presence of oxygen under alkaline condition, 
has aroused much interest. ${ }^{20}$ In addition, its prominent adhesive property makes its easy adherence to almost all types of inorganic or organic substrates. Herein, $\mathrm{Fe}_{3} \mathrm{O}_{4}$ was treated with dopamine to form $\mathrm{Fe}_{3} \mathrm{O}_{4} @ \mathrm{PDA}$, and then magnetic graphene was synthesized by using the hydrothermal treatment of $\mathrm{Fe}_{3}$ $\mathrm{O}_{4} @$ PDA with GO. Especially, during the self-polymerization process of dopamine, catechol groups were oxidized as orthoquinones that provided versatile platform to react with thioland amino-groups of antigens via Michael addition or Schiff base reaction. ${ }^{21}$

In addition, another significant influence for the sensitivity of the immunosensor is the amount of signal tags onto the sensor surface. Numerous techniques have been explored to amplify the detection signal. For instance, polymerase chain reaction $(\mathrm{PCR})$ is the most widely used technique that has been applied to detect DNA or RNA ${ }^{22,23}$ due to its rapid amplification. However, PCR needs expensive instrument, thermal cycling process and rigorous thermostable DNA polymerases. ${ }^{24}$ In contrast, rolling circle amplification (RCA), an isothermal DNA amplification technique, ${ }^{25}$ can also extend the amount of DNA by generating tens of thousands of repetitive sequences under mild condition. Moreover, the generated repetitive sequences by RCA can hybrid with complementary labelled detection probe DNA to enhance signal response. ${ }^{26}$

In this work, magnetic graphene was synthesized by using the hydrothermal treatment of $\mathrm{Fe}_{3} \mathrm{O}_{4}$ @PDA with GO to immobilize antigens. Then, gold nanorods (AuNR) were utilized to immobilize secondary-antibody and circularization DNA template as the signal label. Rolling circle amplification strategy was carried out to generate massive repeated DNA sequences, and then hybridized with the detection probe, thus the signal of the immunosensor was greatly enhanced. The constructed dual signal amplification immunosensor can be employed to detect MC-LR in real water sample.

\section{Experimental}

\subsection{Materials and apparatus}

The antigen (Ag) and the antibody (primary antibody, $A b_{1}$ ) of MC-LR were gifts from the Guangdong Provincial Key Laboratory of Food Quality and Safety. HRP-labelled goat anti-rabbit secondary antibody $\left(\mathrm{Ab}_{2}\right)$ was purchased from Santa Cruz. MC-LR and its related interferences were bought from Enzo Life Sciences Company. Gold(III) chloride tetrahydrate $\left(\mathrm{AuCl}_{3}\right.$ $\left.\cdot \mathrm{HCl} \cdot 4 \mathrm{H}_{2} \mathrm{O}, 99.9 \%\right)$, silver nitrate, sodium dodecyl sulphate (SDS) and hexadecyltrimethyl ammonium bromide (CTAB) were purchased from Shanghai Chemical Reagent Co. Ltd. Dopamine hydrochloride $\left(\mathrm{C}_{8} \mathrm{H}_{11} \mathrm{NO}_{2} \cdot \mathrm{HCl}\right)$ were bought from Aladdin Chemistry Co. Ltd. T4 DNA ligase and phi29 DNA polymerase were purchased from Thermo Fisher scientific company. Streptavidin-HRP (ST-HRP), deoxyribonucleoside-5' ${ }^{\prime}$-triphosphates (dNTP) and the following oligonucleotide sequences were obtained from Shanghai Sangon Biological Engineering Technology \& Services Co. Ltd. (China).

Thiolated primer, $5^{\prime}$-SH- $\left(\mathrm{CH}_{2}\right)_{6}$-AAA AAA AAA AAA AAA CAC AGC TGA GGA TAG GAC AT-3';
Circular template, $5^{\prime}$-CTC AGC TGT GTA ACA ACA TGA AGA TTG TAG GTC AGA ACT CAC CTG TTA GAA ACT GTG AAG ATC GCT TAT TAT GTC CTA TC-3';

Biotinylated DNA probe, 5'-biotin-TTT TTT TCA GAA CTC ACC TGT TAG-3'.

The solution of $0.01 \mathrm{M}$ phosphate buffer saline (PBS, $\mathrm{pH}=$ 7.4) contains $0.1370 \mathrm{M}$ of $\mathrm{NaCl}, 0.0027 \mathrm{M}$ of $\mathrm{KCl}, 0.0100 \mathrm{M}$ of $\mathrm{KH}_{2} \mathrm{PO}_{4}$ and $\mathrm{Na}_{2} \mathrm{HPO}_{4}$, while PBST (pH 7.4) was prepared by adding $0.05 \%$ Tween 20 into PBS (v/v). 5\% skim milk was diluted in 0.01 M PBS as the blocking reagent. The solution of $1 /$ $15 \mathrm{M}$ PBS contains $0.1370 \mathrm{M}$ of $\mathrm{NaCl}, 0.0027 \mathrm{M}$ of $\mathrm{KCl}, 1 / 15 \mathrm{M}$ of $\mathrm{KH}_{2} \mathrm{PO}_{4}$ and $\mathrm{Na}_{2} \mathrm{HPO}_{4}$. All the aqueous solutions were prepared in Milli-Q water.

The morphologies of materials were characterized by transmission electron microscope (TEM, Tecnai 12, FEI, Holland), while the UV-vis and FT-IR spectra were characterized by UV2550 Spectrometer (Shimadzu, Japan) and FT-IR Spectrometer (Nicolet Avatar 360, Thermo, America), respectively. A gel electrophoresis was performed on DYY-6D electrophoresis apparatus (Beijing LiuYi Instrument Company, China). All electrochemical measurements were performed by $\mathrm{CHI} 660 \mathrm{E}$ working station (Shanghai Chenhua Instruments, China) by using indium tin oxide (ITO) electrode as working electrode, Ag/ $\mathrm{AgCl}$ electrode as reference electrode and the platinum wire as auxiliary electrode, respectively.

\subsection{Preparation of $\mathrm{Fe}_{3} \mathrm{O}_{4} @ P D A / R G O$ composite}

The spherical $\mathrm{Fe}_{3} \mathrm{O}_{4}$ nanoclusters were synthesized via solvothermal method, ${ }^{27}$ while graphene oxide was synthesized by modified Hummer's method. ${ }^{28}$ To prepare core/shell $\mathrm{Fe}_{3} \mathrm{O}_{4}$ @PDA composites, as shown in Scheme $1 \mathrm{~B}, 10 \mathrm{mg}$ of spherical $\mathrm{Fe}_{3} \mathrm{O}_{4}$ nanoclusters were dispersed in a mixture of $25 \mathrm{~mL}$ of water and $10 \mathrm{~mL}$ of ethanol under ultrasonication. An hour later, $15 \mathrm{~mL}$ of Tris-8.5 $(\mathrm{pH}=8.5)$ solution was added and sonicated for $30 \mathrm{~min}$, and then $16 \mathrm{mg}$ of dopamine hydrochloride was added and stirred for $18 \mathrm{~h}$ under room temperature. The resultant was collected with a magnet, washed and redispersed in $10 \mathrm{~mL}$ deionized water. To synthesize $\mathrm{Fe}_{3} \mathrm{O}_{4}$ @PDA/RGO nanocomposites, $5 \mathrm{mg}$ of graphene oxide was dispersed in $20 \mathrm{~mL}$ of deionized water, and then mixed with the obtained $\mathrm{Fe}_{3} \mathrm{O}_{4} @$ @PDA solution. The mixture was sonicated for one hour, transferred into an autoclave and heated at $130{ }^{\circ} \mathrm{C}$ for $8 \mathrm{~h}$. The product was collected with a magnet, washed and redispersed in $3 \mathrm{~mL}$ deionized water.

\subsection{Synthesis of AuNR@PDA}

AuNR was synthesized as following. ${ }^{29}$ Firstly, the seed solution was prepared by mixing $5 \mathrm{~mL}$ of $0.2 \mathrm{M}$ CTAB solution with $5 \mathrm{~mL}$ of $0.5 \mathrm{M} \mathrm{HAuCl}_{4}$ solution in a colorimetric tube, and then 0.6 $\mathrm{mL}$ of $10 \mathrm{mM}$ fresh $\mathrm{NaBH}_{4}$ solution was injected and shaken vigorously for one minute. After the colour was changed from yellow to brown, the seed solution was aged at $30^{\circ} \mathrm{C}$ under water bath for at least two hours before use.

Secondly, the growth solution was prepared by dissolving $0.7 \mathrm{~g}$ of CTAB and $0.1234 \mathrm{~g}$ of sodium oleate in $25 \mathrm{~mL}$ of deionized water in an Erlenmeyer flask under ultrasonication, 


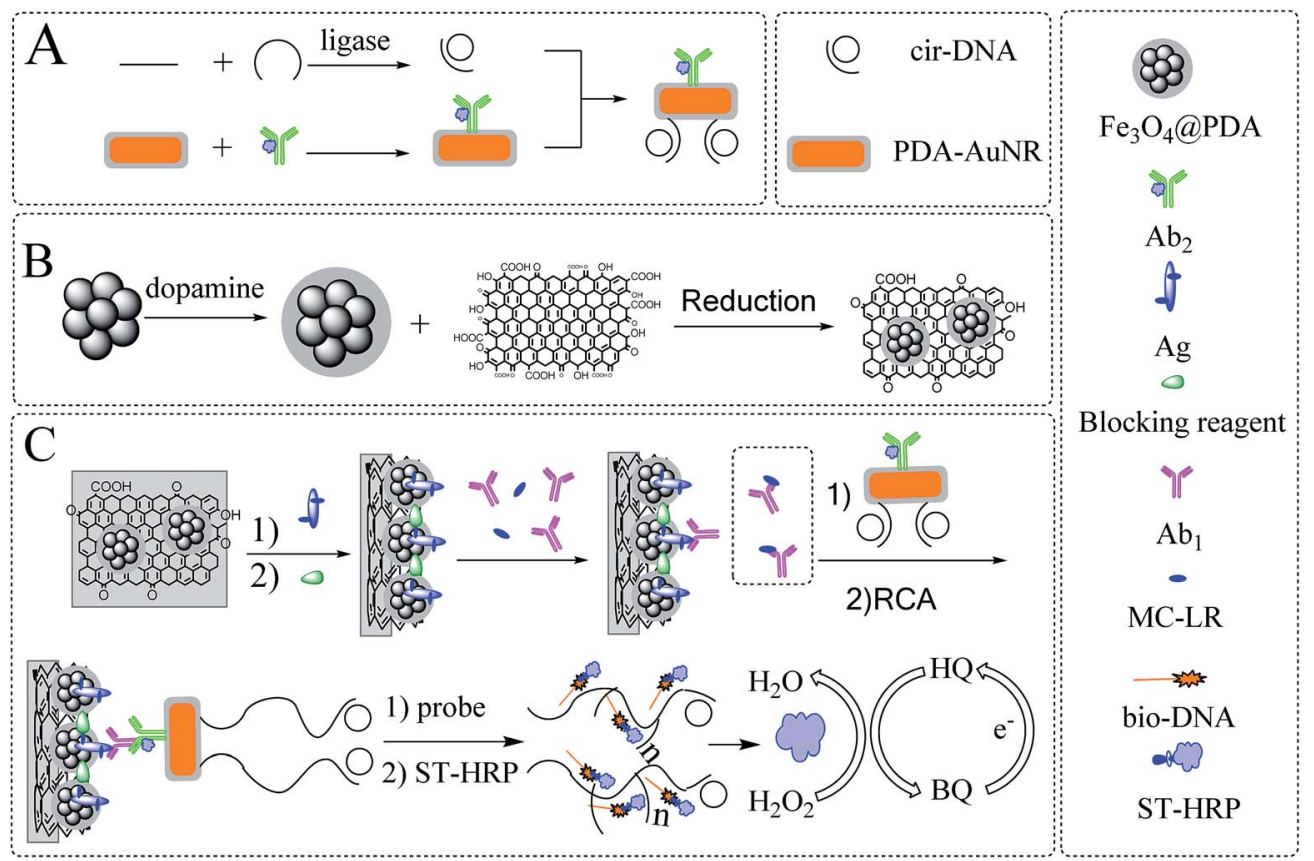

Scheme 1 Illustration of (A) the preparation of $A b_{2}-A u N R-c i r D N A$, (B) the formation of magnetic graphene composite and (C) the construction process of the proposed MC-LR immunosensor.

and $1.5 \mathrm{~mL}$ of $4 \mathrm{mM} \mathrm{AgNO}_{3}$ was added and stirred for $15 \mathrm{~min}$. Then, $25 \mathrm{~mL}$ of $1 \mathrm{mM} \mathrm{HAuCl}_{4}$ solution was added and stirred continuously, and the colour of the growth solution was changed from yellow to colorless after adding $0.15 \mathrm{~mL}$ of concentrated hydrochloric acid, followed by adding $0.35 \mathrm{~mL}$ of $0.0788 \mathrm{M}$ ascorbic acid and stirring for $1 \mathrm{~min}$.

Finally, $60 \mu \mathrm{L}$ of seed solution was added into the growth solution. The mixture was kept stirring for one minute and aged at $30{ }^{\circ} \mathrm{C}$ overnight. After centrifugation and washing, the product was redispersed in $20 \mathrm{~mL}$ water as AuNR stock solution. Then, $0.5 \mathrm{~mL}$ of AuNR solution was mixed with $5 \mathrm{~mL}$ of $0.5 \mathrm{mM}$ dopamine hydrochloride. The solution was sonicated for one hour and centrifuged at $8000 \mathrm{rpm}$ for $10 \mathrm{~min}$ to remove the supernatant. After washing, the AuNR@PDA was resuspended in a mixture with $0.5 \mathrm{~mL}$ of Tris-8.5 and $0.5 \mathrm{~mL}$ of $0.01 \mathrm{M}$ PBST.

\subsection{Preparation of $\mathrm{Ab}_{2}-\mathrm{AuNR}$-cirDNA conjugate}

The circularization DNA template (cirDNA) was prepared as follows. ${ }^{26}$ Primer oligonucleotide $(1 \mu \mathrm{M})$ and template oligonucleotide $(1 \mu \mathrm{M})$ were mixed in $100 \mu \mathrm{L}$ of ligation buffer solution $\left(40 \mathrm{mM}\right.$, Tris- $\mathrm{HCl}, 10 \mathrm{mM} \mathrm{MgCl}_{2}, 10 \mathrm{mM}$ DTT (dithiothreitol), $0.5 \mathrm{mM}$ ATP (adenosine triphosphate), and incubated at $37^{\circ} \mathrm{C}$ for $1 \mathrm{~h}$ ). Subsequently, 10 Weiss units of T4 DNA ligase was added and incubated at $37^{\circ} \mathrm{C}$ for another $1 \mathrm{~h}$. After ligation, T4 DNA ligase was inactivated by heating at $65^{\circ} \mathrm{C}$ for $10 \mathrm{~min}$. The obtained cirDNA mixture could be directly used or stored at $-20^{\circ} \mathrm{C}$. To prepare $\mathrm{Ab}_{2}-\mathrm{AuNR}$-cirDNA conjugate, as shown in Scheme $1 \mathrm{~A}, 10 \mu \mathrm{L}$ of $\mathrm{Ab}_{2}$ was mixed with $1 \mathrm{~mL}$ of AuNR@PDA solution and stirred at $4{ }^{\circ} \mathrm{C}$ for one hour. Subsequently, $100 \mu \mathrm{L}$ of cirDNA solution was added and stirred overnight. The $\mathrm{Ab}_{2}$-AuNR-cirDNA resultant was obtained through centrifugation and redispersed in $1 \mathrm{~mL}$ of $0.01 \mathrm{M}$ PBST.

\subsection{Fabrication of the immunosensor}

The fabrication process of the immunosensor was described in Scheme 1C. The working area of the ITO electrode was restricted as $0.4 \mathrm{~cm} \times 0.4 \mathrm{~cm}$ by epoxy resin, and washed under sonication by diluted nitric acid $(1: 1)$, ethanol and deionized water, respectively. Then, $10 \mu \mathrm{L}$ of $1 \mathrm{mg} \mathrm{mL}{ }^{-1}$ fresh dopamine-Tris solution ( $\mathrm{pH}=8.5)$ was dropped onto the working area, incubated at $37{ }^{\circ} \mathrm{C}$ for $30 \mathrm{~min}$ to form thin PDA membrane, and followed by adding $10 \mu \mathrm{L}$ of diluted $\mathrm{Fe}_{3} \mathrm{O}_{4} @ P D A / R G O$ composites solution (with ethanol, $\mathrm{v} / \mathrm{v}=9: 1$ ) onto the sensor surface. After that, $10 \mu \mathrm{L}$ of MC-LR antigen solution was poured onto the working area, and incubated at $37^{\circ} \mathrm{C}$ for $1 \mathrm{~h}$, followed by adding $10 \mu \mathrm{L}$ of $5 \%$ skim milk to block the nonspecific binding sites. The competitive immunoreaction was performed by mixing certain volumes of $\mathrm{Ab}_{1}$ with different known concentrations of MC-LR (dissolved in methanol and diluted in $0.01 \mathrm{M}$ PBS) stock solution, and then incubating with $10 \mu \mathrm{L}$ of $\mathrm{Ab}_{2}$-AuNR-cirDNA solution for another $1 \mathrm{~h}$.

The rolling circle amplification was initiated by the addition of $10 \mu \mathrm{L}$ of RCA reaction buffer (33 mM Tris-acetate, $\mathrm{pH}=7.9$, $10 \mathrm{mM}$ Mg-acetate, $66 \mathrm{mM}$ K-acetate, $0.1 \%(\mathrm{v} / \mathrm{v})$ Tween $20,1 \mathrm{mM}$ DTT, 1 unit of phi29 DNA polymerase). After incubating for $1 \mathrm{~h}$ at $37{ }^{\circ} \mathrm{C}, 10 \mu \mathrm{L}$ of $0.5 \mu \mathrm{M}$ biotinylated DNA probe was poured onto the electrode and hybridized at $37^{\circ} \mathrm{C}$ for $1 \mathrm{~h}$, followed with $10 \mu \mathrm{L}$ of $20 \mu \mathrm{g} \mathrm{mL} \mathrm{m}^{-1} \mathrm{ST}-\mathrm{HRP}$ at $37^{\circ} \mathrm{C}$ for $1 \mathrm{~h}$. The electrochemical behaviour of the immunosensor was performed by recording cyclic voltammogram (CV) before and after the addition of $2 \mathrm{mM} \mathrm{H}_{2} \mathrm{O}_{2}$ into $10 \mathrm{~mL}$ of $1 / 15 \mathrm{M}$ PBS solution (pH = 
7.4) containing $1 \mathrm{mM}$ hydroquinone in the range from $-1.0 \mathrm{~V}$ to $0.8 \mathrm{~V}$ at a scanning rate of $100 \mathrm{mV} \mathrm{s}^{-1}$.

\section{Results and discussion}

\subsection{Characterization of the $\mathrm{Fe}_{3} \mathrm{O}_{4} @ P D A / R G O$ composite}

In Fig. $1 \mathrm{~A}$, the diameter of the spherical monodispersed magnetic $\mathrm{Fe}_{3} \mathrm{O}_{4}$ nanoclusters was about $130 \pm 10 \mathrm{~nm}$. After reacting with dopamine, a $10 \mathrm{~nm}$ thick PDA layer was generated via self-polymerization process to form core/shell structure (Fig. 1B). The as-prepared $\mathrm{Fe}_{3} \mathrm{O}_{4}$ @PDA composites further reacted with graphene oxide via hydrothermal method. Herein, dopamine can be served as a mild and green reductant to reduce $\mathrm{GO},{ }^{20}$ but also its aromatic ring and GO provided strong $\pi-\pi$ stacking interaction that it was easy for GO to stick onto the surface of PDA. ${ }^{30}$ As in Fig. 1C, $\mathrm{Fe}_{3} \mathrm{O}_{4} @ P D A$ was successfully anchored on wrinkle-like RGO.

The FT-IR spectroscopy was further performed to characterize the composite. As seen in Fig. 1D, curve b was for $\mathrm{Fe}_{3} \mathrm{O}_{4}$, where the wavenumber of $576 \mathrm{~cm}^{-1}$ was corresponded to the $\mathrm{Fe}-\mathrm{O}$ vibration. After the formation of PDA layer upon $\mathrm{Fe}_{3} \mathrm{O}_{4}$ (curve c), two new peaks at $1294 \mathrm{~cm}^{-1}$ and $1510 \mathrm{~cm}^{-1}$ were found and the peak near $1600 \mathrm{~cm}^{-1}$ moved to $1617 \mathrm{~cm}^{-1}$, which were assigned to the phenolic $\mathrm{C}-\mathrm{OH}$ stretching vibration, the amino $\mathrm{N}-\mathrm{H}$ shearing and aromatic ring vibration, ${ }^{31}$ respectively. As for the $\mathrm{Fe}_{3} \mathrm{O}_{4} @ P D A / \mathrm{RGO}$ composite (curve d), the characteristic peak at $3410 \mathrm{~cm}^{-1}$ for $\mathrm{O}-\mathrm{H}$ stretching vibration of GO (curve a) was obviously reduced, while the peaks for epoxy vibration of GO $\left(1224 \mathrm{~cm}^{-1}\right.$, curve a) missed, indicating that GO was partly reduced after the hydrothermal reaction with $\mathrm{Fe}_{3}$ $\mathrm{O}_{4}$ @PDA. The electrical conductivity of $\mathrm{Fe}_{3} \mathrm{O}_{4}$ @PDA/RGO composite was increased when GO was reduced to RGO. ${ }^{18}$ In addition, the as-prepared $\mathrm{Fe}_{3} \mathrm{O}_{4} @ P D A / \mathrm{RGO}$ composite was

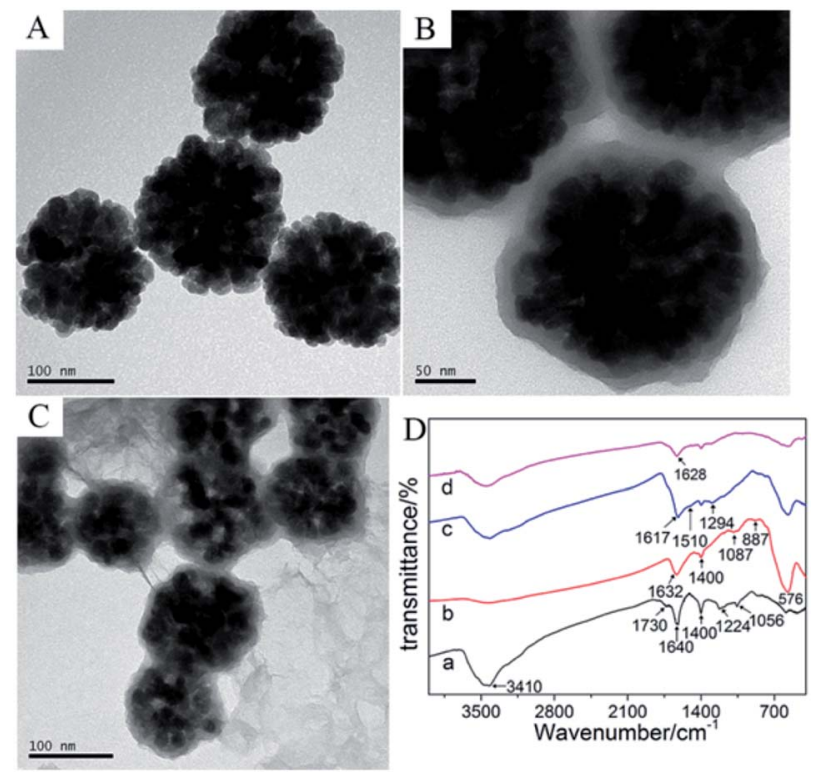

Fig. 1 TEM image of (A) $\mathrm{Fe}_{3} \mathrm{O}_{4}$, (B) $\mathrm{Fe}_{3} \mathrm{O}_{4}$ (aPDA, (C) $\mathrm{Fe}_{3} \mathrm{O}_{4}$ ( $\mathrm{CPDA} / \mathrm{RGO}$, (D) FT-IR spectra of (a) $\mathrm{GO}$, (b) $\mathrm{Fe}_{3} \mathrm{O}_{4}$, (c) $\mathrm{Fe}_{3} \mathrm{O}_{4}$ (aPDA and (d) $\mathrm{Fe}_{3}-$ $\mathrm{O}_{4} @$ PDA/RGO. easily separated by a magnet without traditional centrifugation process and its original morphology and characteristics were perfectly reserved. Besides, the $\mathrm{C}=\mathrm{O}$ stretching vibration $(1628$ $\mathrm{cm}^{-1}$ ) corresponding to the ortho-quinones of PDA was found, ${ }^{32}$ which could become powerful bridges to react with thiol- and amino-groups of antigens via Michael addition or Schiff base reaction. ${ }^{21}$ Therefore, by using the abundant ortho-quinones of PDA, the large surface-to-volume ratio of $\mathrm{Fe}_{3} \mathrm{O}_{4}$, and the excellent conductivity of RGO, sufficient MC-LR antigens can be immobilized onto the magnetic graphene modified electrode.

\subsection{Characterization of the $\mathrm{Ab}_{2}-\mathrm{AuNR}$-cirDNA composite and RCA product}

AuNRs were synthesized via seed growth method. From the TEM in Fig. 2A, AuNRs were monodispersed with the width of $30 \mathrm{~nm}$ and the length of $80 \mathrm{~nm}$. AuNRs have two special optical surface plasmon bands ${ }^{33}$ including the transverse plasmon (TP) band due to the light absorption and scattering along the short axis of the rods and the longitudinal plasmon (LP) band corresponding to the light absorption and scattering along the long axis of the rods. The as-prepared AuNRs possessed a TP band at $523 \mathrm{~nm}$ and a LP band at $712 \mathrm{~nm}$. However, in this seedmediated method, CTAB was used as surfactant to cap AuNRs, but it can hinder AuNRs to link with other biomolecules. ${ }^{33}$ Dopamine is easy to self-polymerize under basic condition, thus it was used to modify the AuNRs as a biocompatible material. From the TEM in Fig. 2B, the PDA layer on AuNRs was about $4 \mathrm{~nm}$.

As mentioned above, PDA can generate ortho-quinones that provide a versatile platform to link with biomolecules. ${ }^{21}$ Therefore, PDA-coated AuNRs were used to associate $\mathrm{Ab}_{2}$ and thiol-cirDNA. In the ultraviolet-visible (UV-vis) spectrum
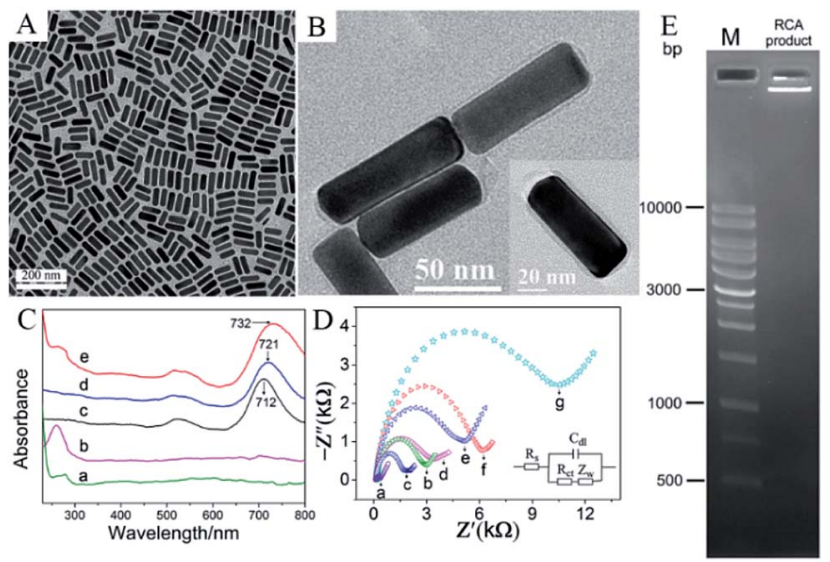

Fig. 2 TEM image of (A) Au NR, (B) AuNRQPDA, (C) UV-vis spectra of (a) $\mathrm{Ab}_{2}$, (b) cirDNA, (c) AuNR, (d) AuNR@PDA and (e) Ab $\mathrm{b}_{2}-\mathrm{AuNR}-$ cirDNA, (D) EIS for (a) bare ITO, (b) PDA/ITO, (c) $\left(\mathrm{Fe}_{3} \mathrm{O}_{4}\right.$ (QPDA/RGO)/ $\mathrm{PDA} / \mathrm{ITO}$, (d) $\mathrm{Ag} /\left(\mathrm{Fe}_{3} \mathrm{O}_{4}(\mathrm{aPDA} / \mathrm{RGO}) / \mathrm{PDA} / \mathrm{ITO}\right.$, (e) $\mathrm{Ab} /$ blocking reagent/Ag/(Fe $\mathrm{O}_{4} @ \mathrm{QPDA} / \mathrm{RGO} / \mathrm{PDA} / \mathrm{ITO}$, (f) $\mathrm{Ab} \mathrm{b}_{2}-\mathrm{AuNR}-\mathrm{cirDNA} / \mathrm{Ab}_{1} /$ blocking reagent/Ag/( $\mathrm{Fe}_{3} \mathrm{O}_{4}(\mathrm{OPDA} / \mathrm{RGO}) / \mathrm{PDA} / \mathrm{ITO}$, (g) $\mathrm{RCA} / \mathrm{Ab}_{2}-$ AuNR-cirDNA/Ab $/$ /blocking reagent/Ag/( $\left.\mathrm{Fe}_{3} \mathrm{O}_{4} @ \mathrm{OPDA} / \mathrm{RGO}\right) / \mathrm{PDA} /$ ITO. (E) The image of gel electrophoresis experiment for DNA marker (M) and RCA product. 
(Fig. 2C), curve d showed that the LP band of PDA-coated AuNRs was shifted to $721 \mathrm{~nm}$ and broader than that of the unmodified AuNRs (curve c). After connecting with $\mathrm{Ab}_{2}$ and cirDNA, the LP band of AuNRs in curve e was further shifted to $732 \mathrm{~nm}$ and became broader. In addition, a broad peak between $280 \mathrm{~nm}$ and $260 \mathrm{~nm}$ was found, which was corresponded to the overlap of characterized absorption of $\mathrm{Ab}_{2}$ (curve a) and the typical absorption of cirDNA (curve b), indicating the formation of $\mathrm{Ab}_{2}-$ AuNR-cirDNA conjugate.

The cirDNA conjugated onto AuNRs was further taken to trigger RCA to enhance signal response for the immunoassay. Herein, the agarose gel electrophoretic experiment was performed to verify the rolling circle amplification. The experiment process was as follow. $1 \%$ agarose gel was prepared in $0.5 \times \mathrm{TBE}$ buffer containing $0.01 \% 4 \mathrm{~S}$ Green nucleic acid stain and then ran at $120 \mathrm{~V}$ for $45 \mathrm{~min}$. From Fig. 2E, compared with the marker lane, the bright lane of RCA product indicated that it was a very long DNA sequence whose structure contained more than $10000 \mathrm{bp}$, confirming that rolling circle amplification was carried out.

\subsection{Electrochemical study for the fabrication of the immunosensor}

The electrochemical impedance spectroscopy (EIS) was used to investigate the assemble process of the immunosensor. It was performed in $5 \mathrm{mM}\left[\mathrm{Fe}(\mathrm{CN})_{6}\right]^{3-/ 4-}$ solution containing $0.1 \mathrm{M}$ $\mathrm{KCl}$, with the frequency ranged from $0.1 \mathrm{~Hz}$ to $100 \mathrm{kHz}$ at an amplitude of $50 \mathrm{mV}$ and a bias potential of $0.2 \mathrm{~V}$. The Nyquist plotting of EIS was recorded in Fig. 2D, where the inset is the equivalent circuit model. The $R_{\mathrm{s}}, R_{\mathrm{ct}}, C_{\mathrm{dl}}$, and $Z_{\mathrm{w}}$ are the electrolyte solution resistance, the electrode surface charge transfer resistance, the double-layer capacitance and the Warburg impedance, respectively. In the Nyquist plot, a straight line portion at lower frequency range represents the diffusion-limit process. A semicircle section at higher frequency range describes the electrode surface charge transfer resistance $\left(R_{\mathrm{ct}}\right)$ which corresponds to the electron transfer-limit process. The $R_{\mathrm{ct}}$ increases when the surface of electrode prevents the attachment of the redox. From curve a, it showed that the bare ITO electrode owned very small semicircle, indicating its very low electron limit to redox probe. After modifying with PDA, the semicircle (curve b) increased clearly, which meant that the PDA membrane hindered the redox probe to electrode surface. After modification by magnetic graphene composites (curve c), the diameter of semicircle decreased, since RGO possessed good conductivity. When the antigen was immobilized onto the electrode, the $R_{\mathrm{ct}}$ increased obviously (curve d), indicating the immobilization of antigens prevented the electron transfer on the electrode. After reacting with $\mathrm{Ab}_{1}$ (curve e) and $\mathrm{Ab}_{2}-\mathrm{AuNR}$-cirDNA conjugate (curve $\mathrm{f}$ ), the $R_{\mathrm{ct}}$ further increased, suggesting that formation of the immune complex on the electrode surface can retard the electron transfer. After rolling circle amplification, the $R_{\mathrm{ct}}$ increased remarkably (curve g) since the negative-charged phosphate backbone of single chain DNA prevented the transfer of $\left[\mathrm{Fe}(\mathrm{CN})_{6}\right]^{3-/ 4-}$ redox probe. All these results confirmed that the fabrication of the immunosensor was accomplished.

\subsection{Optimization of the detection conditions for the immunosensor}

In order to achieve a sensitive and stable competitive immunosensor, the concentration of $\mathrm{Ag}, \mathrm{Ab}_{1}$, incubation time of $\mathrm{Ab}_{1}$, and the $\mathrm{pH}$ of the detecting system were investigated by using the magnetic graphene composite as substrate and the commercial HRP-labelled $\mathrm{Ab}_{2}$ as the label. Firstly, the influence of the dilution ratio of antigen was shown in Fig. 3A, where the current response increased quickly when the dilution ratio raised from $1: 1600$ to $1: 50$. The higher dilution ratio of antigen was, the more antigen could be captured onto the electrode. However, the excessive antigen may cause steric hindrance which may lead to the instability for the immunoreaction. On the contrary, the signal response would become very low which could cause high background noise when the immobilized amount of $\mathrm{Ag}$ was inadequate. It showed that the current response was very close between the ratio of $1: 50$ and $1: 100$. Therefore, the dilution ratio of $1: 100$ was selected as the optimal concentration of antigen.

Secondly, the dilution ratio of $\mathrm{Ab}_{1}$ was explored. In Fig. 3B, when the ratio of antibody was diluted from $1: 100$ to $1: 1600$, the current response decreased remarkably, while the dilution ratio of $1: 100$ and $1: 200$ received almost the same signal response, indicating that the 1:100 dilution ratio may be oversaturate. The oversaturated concentration of $\mathrm{Ab}_{1}$ can affect the sensitivity of competitive immunoreaction. So, the $1: 200$ dilution ratio of $\mathrm{Ab}_{1}$ was chosen.

Subsequently, the reaction time of $\mathrm{Ab}_{1}$ and $\mathrm{Ag}$ was investigated. In Fig. 3C, as the reaction time promoted, the signal response increased. There existed a plateau when the reaction time reached $60 \mathrm{~min}$, or rather, the signal response decreased slowly, when the reaction time was longer. The activity of $A b_{1}$ may weaken when the incubation time was too long. Hence, an hour for incubating was enough.
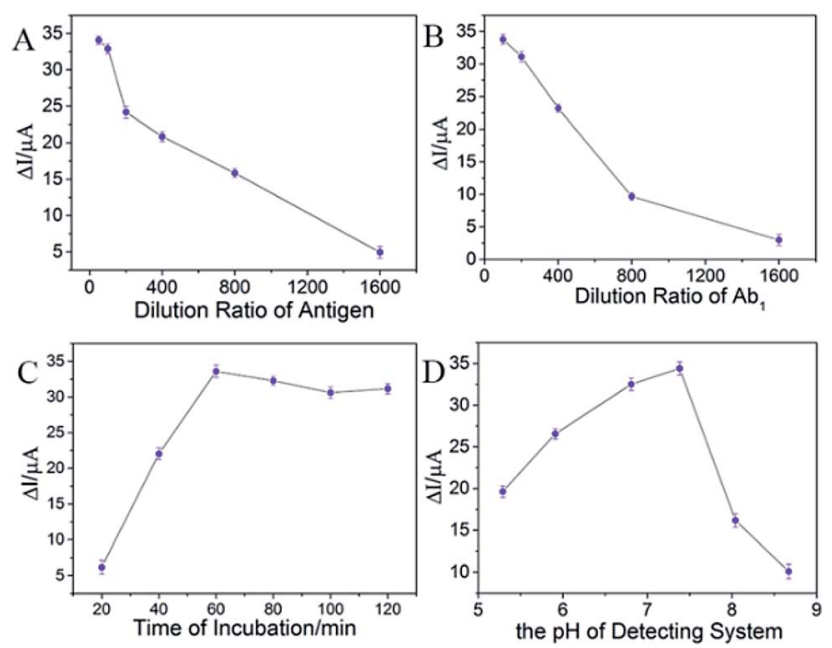

Fig. 3 The influence of the conditions on the proposed immunosensor. (A) The dilution ratio of antigen, (B) the dilution ratio of primary antibody, (C) the incubation time of primary antibody and (D) the $\mathrm{pH}$ of detecting system. 
Finally, the $\mathrm{pH}$ of detecting environment was investigated. In Fig. 3D, it showed that when the $\mathrm{pH}$ of detecting solution approached neutral, the ideal signal response was recorded. Too much acid or base can decrease the activity of enzyme that resulted in the instability of the immunosensor. Furthermore, the alkaline condition prevented the proton to transfer that the signal response decreased remarkably. So, the optimal $\mathrm{pH}$ of 7.38 was chosen.

\subsection{The signal enhancement of the immunosensor}

The electrochemical behaviour was performed by recording $\mathrm{CV}$ before and after the addition of $2 \mathrm{mM}$ of $\mathrm{H}_{2} \mathrm{O}_{2}$ into 1/15 M PBS solution containing $1 \mathrm{mM}$ hydroquinone. The signal response was recorded from $\mathrm{CV}$ through the horseradish peroxidase catalysing the decomposition of hydrogen peroxide. The possible mechanism was described as follows: ${ }^{16}$

$$
\begin{gathered}
\mathrm{HRP}\left(\mathrm{Fe}^{3+}\right)+\mathrm{H}_{2} \mathrm{O}_{2} \rightarrow \operatorname{compound}(\mathrm{I})+\mathrm{H}_{2} \mathrm{O} \\
\text { Compound(I) }+\mathrm{HQ} \rightarrow \operatorname{compound}(\mathrm{II})+\mathrm{BQ} \\
\text { Compound(II) }+\mathrm{HQ} \rightarrow \mathrm{HRP}\left(\mathrm{Fe}^{3+}\right)+\mathrm{BQ}+\mathrm{H}_{2} \mathrm{O} \\
\mathrm{BQ}+2 \mathrm{H}^{+}+2 \mathrm{e}^{-} \rightarrow \mathrm{HQ} \text { (electrode reaction) }
\end{gathered}
$$

Herein, the oxidation state and the reduction state of hydroquinone were $\mathrm{HQ}$ and $\mathrm{BQ}$, respectively. With the aid of $\mathrm{H}_{2} \mathrm{O}_{2}$, HRP was oxidized as compound(I). Then $\mathrm{HQ}$ reacted with compound(I) to generate $\mathrm{BQ}$. Therefore, as for the electrode reaction, the oxidation peak decreased since $\mathrm{HQ}$ was consumed in eqn (2) and (3). On the contrary, the reduction peak increased since a lot of $\mathrm{BQ}$ transformed to $\mathrm{HQ}$ via a two-electron transfer process. In order to estimate the performance of the fabricated immunosensor, three categories of immunosensors were constructed to confirm the signal amplification effect. As shown in Fig. 4A, if PDA was used as the substrate to immobilize antigen and $\mathrm{HRP}-\mathrm{Ab}_{2}$ as the label, the current response $(\Delta I)$ was 16.32 $\mu \mathrm{A}$, while if the substrate was replaced by $\left(\mathrm{Fe}_{3} \mathrm{O}_{4} @ \mathrm{PDA} / \mathrm{RGO}\right) /$ PDA, the current response was $33.74 \mu \mathrm{A}$. The current response increased substantially that ascribed to two reasons. One reason was that the large surface area of magnetic graphene provided abundant adsorption sites for antigen. The other was that RGO effectively changed the surface electrical conductivity of electrode. Moreover, in Fig. 4C, if $\mathrm{Ab}_{2}$-AuNR-cirDNA was used as the label and the RCA was employed, the current response reached $64.65 \mu \mathrm{A}$. RCA can produce repeated units of single chain DNA which can provide plenty of sites for biotinylated DNA probe to hybridize, and then a large number of ST-HRPs were captured by biotinylated DNA probe to improve the signal response. Therefore, magnetic graphene substrate and rolling circle amplification strategy enhanced the signal response of the immunosensor dramatically.

\subsection{The performance of the immunosensor}

The microcystin-LR analysis was carried out under the optimal condition based on the magnetic graphene substrate using $\mathrm{Ab}_{2}-$ AuNR-cirDNA as the label. In a conventional competitive
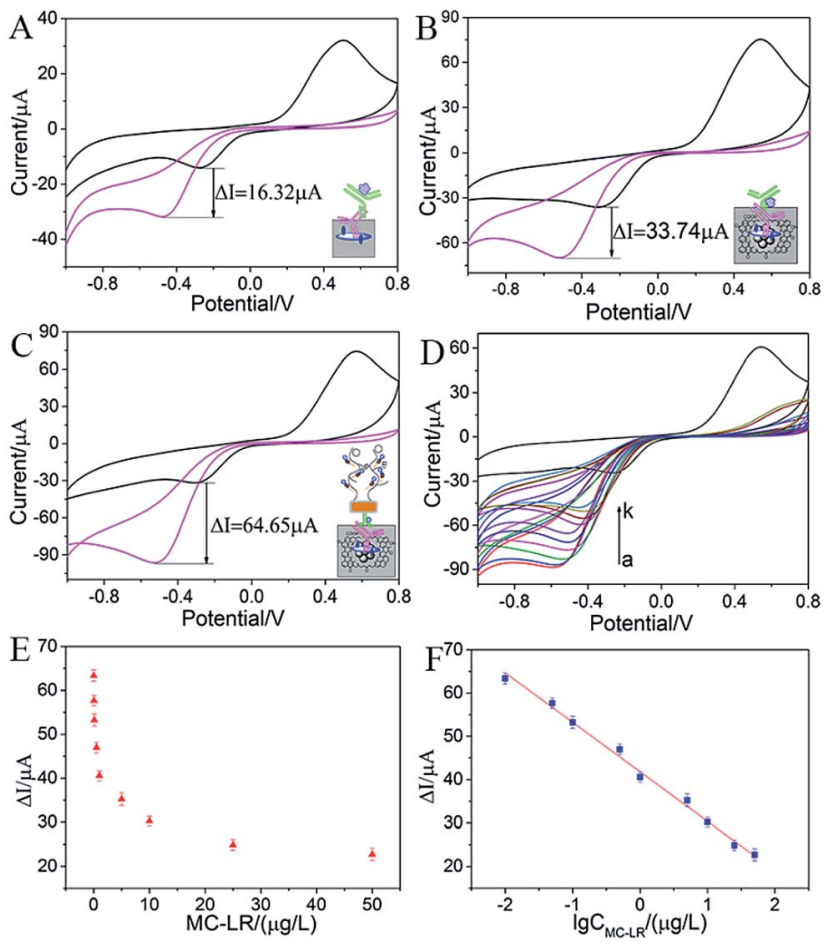

Fig. 4 Different immunosensors of (A) PDA as substrate with HRP-Ab label, (B) $\left(\mathrm{Fe}_{3} \mathrm{O}_{4} \mathrm{QPDA} / \mathrm{RGO}\right) / \mathrm{PDA}$ as substrate with $\mathrm{HRP}-\mathrm{Ab}_{2}$ label and (C) $\left(\mathrm{Fe}_{3} \mathrm{O}_{4}(\mathrm{QPDA} / \mathrm{RGO}) / \mathrm{PDA}\right.$ as substrate with $\mathrm{Ab}_{2}$-AuNR-cirDNA label and rolling circle amplification (black lines were $\mathrm{CV}$ before while red lines were after the addition of $2 \mathrm{mM} \mathrm{H}_{2} \mathrm{O}_{2}$ in $1 \mathrm{mM}$ hydroquinone solution). (D) The immunosensor (C) was incubated with different concentrations of MC-LR and then CVs were recorded in 1/15 M PBS solution containing $1 \mathrm{mM}$ hydroquinone after the addition of $2 \mathrm{mM}$ $\mathrm{H}_{2} \mathrm{O}_{2}$ (from a to j: $0,0.01,0.05,0.1,0.5,1,5,10,25$ and $50 \mu \mathrm{g} \mathrm{L}^{-1}$ ), while curve $\mathrm{k}$ was the $\mathrm{CV}$ before the addition of $\mathrm{H}_{2} \mathrm{O}_{2}$. (E) The relationship between the current response $(\Delta /)$ and the concentration of MC-LR $\left(C_{M C-L R}\right)$. (F) The calibration curve of the proposed immunosensor.

immunosensor, the analyte in the solution can compete with antigen immobilized on the electrode to combine with a certain amount of $\mathrm{Ab}_{1}$. Herein, different concentrations of MC-LR solution were mixed with a certain concentration of $\mathrm{Ab}_{1}$, and a certain volume of mixture was used to incubate with the immobilized antigen. As shown in Fig. 4D, when the concentration of MC-LR increased, the cathodic currents in CVs decreased, suggesting a lower amount of $\mathrm{Ab}_{1}$ was adsorbed on the electrode surface. The current response $(\Delta I)$ was denoted as the current change before and after the addition of $\mathrm{H}_{2} \mathrm{O}_{2}$, showing a clear decrease with the increase in the concentration (Fig. 4E). Especially, the current response showed a linear relationship with the logarithm of MC-LR concentration in the range between $0.01 \mu \mathrm{g} \mathrm{L}^{-1}$ and $50 \mu \mathrm{g} \mathrm{L}^{-1}$ (Fig. $4 \mathrm{~F}$ ). The equation was $\Delta I=41.82-11.44 \times \log C\left(R^{2}=0.993\right)$, where $C$ was the concentration of MC-LR. According to the equation: $x=3 s / b$, where " $s$ " represents the standard deviation of background signal and " $b$ " is the sensitivity, the detection limit was calculated to be $0.007 \mu \mathrm{g} \mathrm{L}^{-1}$. The performance of the proposed electrochemical immunosensor was compared with the reported techniques for MC-LR detection. As shown in Table 1, its detection limit and linear range was better than or comparable 
Table 1 Comparison of different reported methods for MC-LR detection

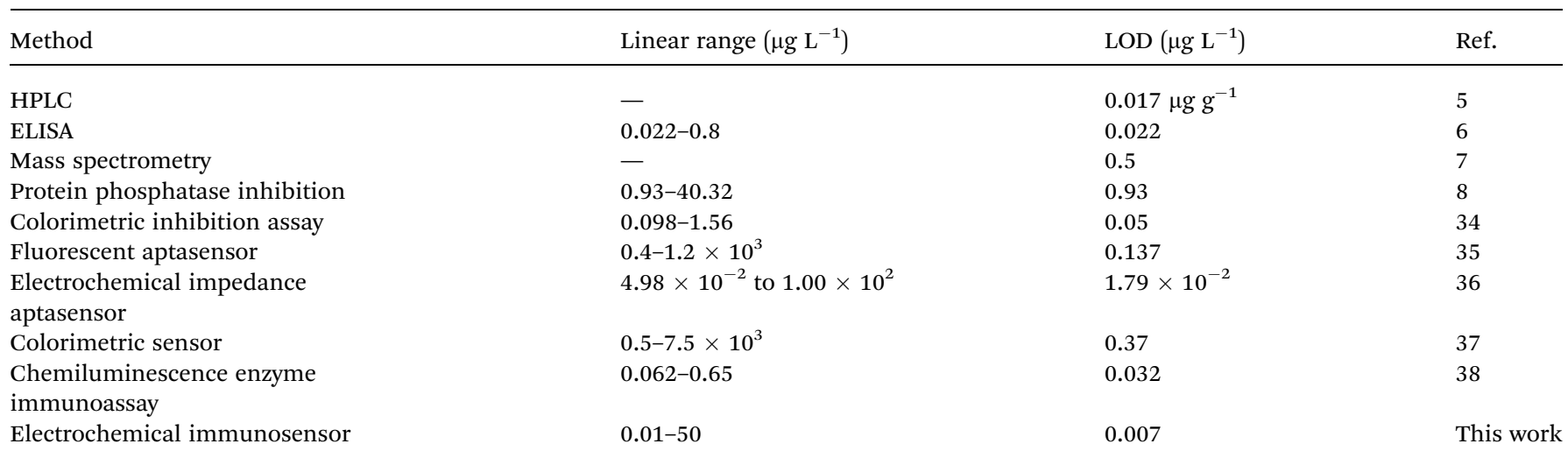

with earlier work. It also met with the need of WHO guideline limit of $1 \mu \mathrm{g} \mathrm{L}^{-1}$ in drinking water, indicating that it was enough for practical application.

To evaluate the specificity of the immunosensor for the detection of MC-LR, the same amount of MC-LR analogues including MC-RR, MC-YR and nodularin were added into MC$\mathrm{LR}$ and $A \mathrm{~b}_{1}$ mixture during the incubation process. The "mixture" meant that four microcystins were mixed. Fig. 5 showed that the current response maintained from $94.7 \%$ to $97.6 \%$, although the interferences were added, indicating that the proposed immunosensor owned excellent selectivity.

The stability of the proposed immunosensor was investigated. The immunosensor modified by $\mathrm{Ag} /\left(\mathrm{Fe}_{3} \mathrm{O}_{4} @ \mathrm{PDA} / \mathrm{RGO}\right) /$ PDA/ITO was prepared and put in the refrigerator at $4{ }^{\circ} \mathrm{C}$ for two weeks. The current response was still kept $93.75 \%$, indicating that the proposed immunosensor was stable. The repeatability of the immunosensor was evaluated by the coefficients of variation (RSD) of the intra-assay and the inter-assay. The intra-assay precise was investigated by three different concentrations of MC-LR, $0.1 \mu \mathrm{g} \mathrm{L}^{-1}, 0.5 \mu \mathrm{g} \mathrm{L} \mathrm{L}^{-1}$ and $1 \mu \mathrm{g} \mathrm{L}^{-1}$ for three parallel experiments, resulting in their RSD of $3.34 \%$, $3.63 \%$ and $3.13 \%$, respectively, indicating a good repeatability. The inter-assay precise was estimated by above concentrations of MC-LR in five immunosensors, of whom the coefficients of variation were $3.56 \%, 3.31 \%$ and $3.52 \%$. Therefore, the repeatability of the immunosensor was acceptable.

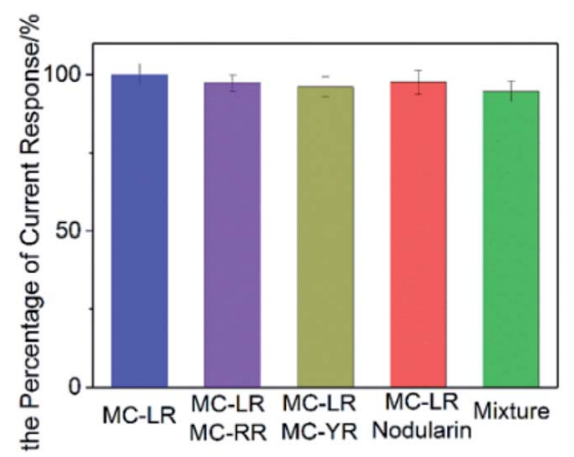

Fig. 5 The specificity of the proposed immunosensor of $1 \mu \mathrm{g} \mathrm{L}^{-1} \mathrm{MC}$ $\mathrm{LR}$ with $1 \mu \mathrm{g} \mathrm{L}^{-1}$ interferences.
Table 2 Recovery results from the electrochemical immunosensor for MC-LR in lake water

\begin{tabular}{lllll}
\hline Sample & Added $\left(\mu \mathrm{g} \mathrm{L}^{-1}\right)$ & Found $\left(\mu \mathrm{g} \mathrm{L}^{-1}\right)$ & Recovery $(\%)$ & RSD (\%) \\
\hline 1 & 1.00 & 1.05 & $105.0 \%$ & 3.13 \\
2 & 5.00 & 4.93 & $98.6 \%$ & 3.76 \\
3 & 10.00 & 9.61 & $96.1 \%$ & 2.82 \\
\hline
\end{tabular}

The proposed immunosensor was monitored its practicability by the recoveries of $1 \mu \mathrm{g} \mathrm{L}^{-1}, 5 \mu \mathrm{g} \mathrm{L}^{-1}$ and $10 \mu \mathrm{g} \mathrm{L}^{-1}$ of MC-LR from the Western Lake water of South China Agricultural University via the standard addition method. As shown in Table 2, the recoveries of the spiked sample were $105.0 \%, 98.6 \%$ and $96.1 \%$, respectively. It meant that the proposed immunosensor could be employed in real water sample.

\section{Conclusions}

In summary, a specific and robust electrochemical immunosensor for MC-LR detection was fabricated based on magnetic graphene substrate and $\mathrm{Ab}_{2}-\mathrm{AuNR}$-cirDNA label. The magnetic graphene composites were used as the substrate to immobilize plenty antigens by taking advantage of their large surface area. Also, the $\mathrm{Ab}_{2}$-AuNR-cirDNA conjugate was utilized to enhance the current response via RCA. Under the optimal conditions, the proposed immunosensor showed excellent performance such as wide linear range from $0.01 \mu \mathrm{g} \mathrm{L}^{-1}$ to $50 \mu \mathrm{g} \mathrm{L}^{-1}$ and low detection limit of $0.007 \mu \mathrm{g} \mathrm{L}^{-1}$. Also, this proposed assembled strategy can be applied to detect MC-LR in real water sample. Therefore, its potential application in environmental monitoring, clinic diagnosis and protein detection can be also expected.

\section{Conflicts of interest}

They are no conflicts to declare. 


\section{Acknowledgements}

This work was supported by the National Scientific Foundation of China (21475047), the Science and Technology Planning Project of Guangdong Province (2016B030303010), the Program for the Top Young Innovative Talents of Guangdong Province (2016TQ03N305) and the Foundation for High-level Talents in South China Agricultural University.

\section{Notes and references}

1 E. Dittmann and C. Wiegand, Mol. Nutr. Food Res., 2006, 50, 7-17.

2 S. Singh, A. Srivastava, H. Oh, C. Ahn, G. Choi and R. K. Asthana, Toxicon, 2012, 60, 878-894.

3 M. K. Cordeiro-Araújo, M. A. Chia, J. D. D. T. Arruda-Neto, V. L. Tornisielo, F. Z. Vilca and M. D. C. BittencourtOliveira, Sci. Total Environ., 2016, 566, 1379-1386.

4 WHO, Guidelines for drinking-water quality, World Health Organization, 2004, vol. 1.

5 E. C. Aguete, A. Gago-Martínez, J. M. Leão, J. A. RodríguezVázquez, C. Menàrd and J. F. Lawrence, Talanta, 2003, 59, 697-705.

6 M. Lotierzo, R. Abuknesha, F. Davis and I. E. Tothill, Environ. Sci. Technol., 2012, 46, 5504-5510.

7 S. Liu, C. Deng and X. Zhang, Talanta, 2016, 154, 183-189.

8 G. Catanante, L. Espin and J. Marty, Biosens. Bioelectron., 2015, 67, 700-707.

9 R. Xiao, Z. Rong, S. Chen, W. Chen and S. Wang, RSC Adv., 2014, 4, 36125-36130.

10 Y. Yang, Q. Liu, Y. Liu, Z. Li, Y. Li, P. Wang, D. Zhang, Z. Zhao, Y. Liu and Y. Dong, RSC Adv., 2016, 6, 31824-31830.

11 H. Yin, B. Sun, Y. Zhou, M. Wang, Z. Xu, Z. Fu and S. Ai, Biosens. Bioelectron., 2014, 51, 103-108.

12 H. Zhao, C. Xue, T. Nan, G. Tan, Z. Li, Q. X. Li, Q. Zhang and B. Wang, Anal. Chim. Acta, 2010, 676, 81-86.

13 C. Wang, M. Lin, Y. Liu and H. Lei, Electrochim. Acta, 2011, 56, 1988-1994.

14 Y. Deng, D. Qi, C. Deng, X. Zhang and D. Zhao, J. Am. Chem. Soc., 2008, 130, 28-29.

15 I. S. Ibarra, J. M. Miranda, J. A. Rodriguez, C. Nebot and A. Cepeda, Food Chem., 2014, 157, 511-517.

16 C. Gan, L. Ling, Z. He, H. Lei and Y. Liu, Biosens. Bioelectron., 2016, 78, 381-389.

17 Y. Wang, Z. Li, J. Wang, J. Li and Y. Lin, Trends Biotechnol., 2011, 29, 205-212.
18 C. I. L. Justino, A. R. Gomes, A. C. Freitas, A. C. Duarte and T. A. P. Rocha-Santos, TrAC, Trends Anal. Chem., 2017, 91, 53-66.

19 V. Georgakilas, J. N. Tiwari, K. C. Kemp, J. A. Perman, A. B. Bourlinos, K. S. Kim and R. Zboril, Chem. Rev., 2016, 116, 5464-5519.

20 E. K. Jeon, E. Seo, E. Lee, W. Lee, M. Um and B. Kim, Chem. Commun., 2013, 49, 3392-3394.

21 E. Faure, C. Falentin-Daudré, C. Jérôme, J. Lyskawa, D. Fournier, P. Woisel and C. Detrembleur, Prog. Polym. Sci., 2013, 38, 236-270.

22 C. Yu, B. Yin, S. Wang, Z. Xu and B. Ye, Anal. Chem., 2014, 86, 7214-7218.

23 A. McBeath, N. Bain, M. Fourrier, B. Collet and M. Snow, J. Virol. Methods, 2013, 187, 65-71.

24 W. Cheng, F. Yan, L. Ding, H. Ju and Y. Yin, Anal. Chem., 2010, 82, 3337-3342.

25 M. M. Ali, F. Li, Z. Zhang, K. Zhang, D. Kang, J. A. Ankrum, X. C. Le and W. Zhao, Chem. Soc. Rev., 2014, 43, 3324-3341.

26 H. Chen, S. Wu, F. Dong, W. Cheng, Q. Li, S. Ding and R. Luo, Sens. Actuators, B, 2015, 221, 328-333.

27 M. Lin, H. Huang, Z. Liu, Y. Liu, J. Ge and Y. Fang, Langmuir, 2013, 29, 15433-15441.

28 C. Gan, Z. Sun, L. Ling, Z. He, H. Lei and Y. Liu, RSC Adv., 2016, 6, 51662-51669.

29 X. Ye, C. Zheng, J. Chen, Y. Gao and C. B. Murray, Nano Lett., 2013, 13, 765-771.

30 Y. Yang, A. M. Asiri, Z. Tang, D. Du and Y. Lin, Mater. Today, 2013, 16, 365-373.

31 T. Zeng, X. Zhang, Y. Ma, H. Niu and Y. Cai, J. Mater. Chem., 2012, 22, 18658-18663.

32 M. Liu, G. Luo, Y. Wang, R. Xu, Y. Wang, W. He, J. Tan, M. Xing and J. Wu, Sci. Rep., 2017, 7, 436.

33 Z. Zhang and M. Lin, RSC Adv., 2014, 4, 17760-17767.

34 A. Sassolas, G. Catanante, D. Fournier and J. L. Marty, Talanta, 2011, 85, 2498-2503.

35 S. M. Taghdisi, N. M. Danesh, M. Ramezani, N. Ghows, S. A. M. Shaegh and K. Abnous, Talanta, 2017, 166, 187-192.

36 Z. Lin, H. Huang, Y. Xu, X. Gao, B. Qiu, X. Chen and G. Chen, Talanta, 2013, 103, 371-374.

37 X. Li, R. Cheng, H. Shi, B. Tang, H. Xiao and G. Zhao, J. Hazard. Mater., 2016, 304, 474-480.

38 F. Long, H. C. Shi, M. He, J. W. Sheng and J. F. Wang, Anal. Chim. Acta, 2009, 649, 123-127. 